\title{
Research on Information System Applied to Regional Tourism Development for Evolution Process
}

\author{
Shuang Liu \\ Xinyang Vocational Technology College, \\ Xinyang, China
}

\begin{abstract}
Information system is a data-intensive, humancomputer interactional computer application system whose main aim is to provide information service. At present, there are two modes of information system using by tourism enterprises: the first one based on the information web mainly used in the network marketing, the second one links organization information system with the tourism demand using epitaxial way. It operates the cooperation organization effectively in the angle of knowledge management and also strengthens the organization performance. Knowledge system is a management application with high level of the online information system. It emphasizes on the coordination and cooperation, and wants to achieve synergies by relevant target management and content management between organizations.
\end{abstract}

Keywords-organization building; evolution process; information system

\section{I.INTRODUCTION}

Information system for the regional tourism cooperation is a computer application system with security, comprehensive data, and human-computer interaction. Tourism economic main bodies from different regions of the area re-configure and combine resources according to the constitution, agreement, or contract, in order to maximize the overall efficiency (economic, social, and ecological benefits).During the course, the flow of information from the cooperative region both inside and outside is collected, collated, analyzed, stored, transmitted, fed back, and tracked. From the content point of view, the online information system is based on the Intranet (regional tourism cooperation intranet) as information infrastructure architecture aimed for wide information sharing (isomorphism and heterogeneous), data warehouse is used for data organization and processing [1]. It emphasizes on data mining and multidimensional data analysis, provides the ways and means to retrieve information from Intranet and Internet, and then supplies important basis and projects for decision-making, and to achieve a comprehensive grasp of the regional tourism cooperation. The system broke through traditional regional tourism information system, which is information mode only for tourists, or management mode just for tourist destination management sector and related industries sector. Therefore, it is really important to define the online information systems in the regional tourism cooperation and highlight its effects on the construction of the organization structure, also the improvements of the organizational performance. So it is believed that the online information system is a computer application system with data-intensive and human-computer interaction, which can strengthen tourism cooperation organization structure, improve organizational performance, as well as achieve organizational synergies [2]. Its basic function is providing information services. Management and decision support are extended functions. This definition helps to explain the importance and significance of online information system for the building of regional tourism cooperation organization and the management of various departments' knowledge, content and performance.

\section{REVIEWS}

The information system of the regional tourism cooperation involved in this paper mainly consists of four parts: (a) cooperation organization online information systems: a lot of contents are organized by topic, and potential tourists (tourists, travel agencies which organize tourists, and other organizations or groups with the function of travel agency) are connected with information [3]. It is the support system for the construction of regional tourism cooperation organization, by online information system of the cooperation organization, the most basic information channels of communication and ties are established between the regional cooperation organizations. On the other hand, the information system of the cooperation organization is an internal and external compatible operating system, it has openness and external expansion, and so its system not only includes members of the organization but also includes market information outside the organization. Therefore, the information flow could be passed by the information system cross inside and outside of the regional tourism cooperation organization. Each organization has specific resources to exploit, develop, and share in order to create value.

These resources can be defined as the capabilities of an organization. Relative to technological capabilities specifically, IT can be classified as technologies for handling, storing, and communicating information. IT capabilities can be divided in two groups: management capabilities and technical capabilities. A more complete definition of IT capabilities is the "firm's ability to acquire, deploy, and leverage its IT-related resources in combination with other resources and capabilities in order 
to achieve business objectives". In this case, the IT capabilities concept contains six sub-dimensions: IT business partnerships, external IT Linkages, IT business strategic thinking, IT business process integration, IT management, and IT infrastructure. These IT capabilities aim to satisfy the firm's information requirements [4]. The idea that there is no best way to manage an organization has been the underlying assumption of a great number of research models in several areas of study. Contingency models, which hypothesize that there is no best way to organize, have also been proposed and tested in IS studies. Contingency models have been used to study the relationship between business strategy, structure, IT strategy, and IT structure, to define strategies for information requirements determination, to identify individual impacts of IT, impacts of IT on learning, impacts of IT problem solving tools on task performance and impacts of IT on organizational performance [5]. Moreover, following information processing model, the alignment between information requirements and information processing capacity has been an objective pursued by a number of researchers, and particularly in the present global business context. The administrative intervention simplifies the organization structure, which should be based on market mechanisms before [6]. The internationalization mode has therefore a determining role in the choice of IT capabilities that are to be deployed locally and internationally. Information system managers who plan to expand or modify their international approach would gain insight by including this fact into their scenario assessment. The non-significant relationship between the internationalization mode and information requirements might indicate that the need for control and communication varies among the information system. It is conceivable that this need is dependent upon the type of industry in which the information system operates. Indeed, firms operating in industries characterized by a more uncertain environment, such as software programming and outsourcing, might have greater information requirements than firms in industries such as food or textile.

\section{COMPARISON OF MODELS}

The stakeholders of regional tourism cooperation use online information systems to reach their potential customers with targeted messages over the web, to process financial accounts, and to manage their human resources. Governments deploy online information systems to provide services cost-effectively to travelers by digital goods, such as software and online services, such as auctions and social networking [7]. The so-called organization elements are essential ingredient and content when organizations are built. Each organization is a system consisted of organization elements, and elements are independent. Leavitt's organization model includes four organization elements, social structure, participants, objectives, and technology.

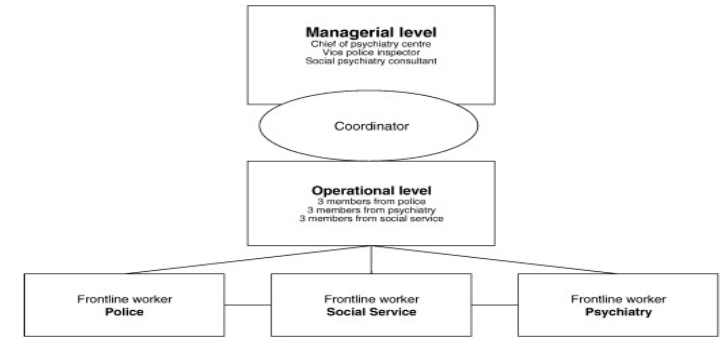

Figure 1. Organization cooperation of consulting system.

It includes human-beings, management level, personal capacity, person selection, training, and use. These views are basically based on the internal elements of real firms [8]. As regional tourism cooperation organization is an online, multi-generalized organization, it should not only consider internal elements but also cover environmental elements of the marginalized organization in a certain degree. It is believed that, the organization elements of the regional tourism cooperation organization includes regionalism, collaboration networks, organization infrastructure, market capacity, transmission mechanism of information, technology, innovation, policy and regulations, credit and morality, social environment, organization goals, and coordination mechanisms. Regional tourism cooperation serves as a tool to fulfill the effect created by the whole region. Theoretically, the entirety is more than simple addition of resources. According to the module type that they provide for the cooperative organization system, organizational elements for the regional tourism cooperation can be divided into three categories, which are premise elements, collaborative elements and foundation elements.

By the help of collaborative information, as a subsystem, online information system provides collaborative tools and information-sharing platform for stakeholders, who take part in the regional tourism cooperation. It strengthens the interactive relationship of travel information between different sub-bodies. By establishing a comprehensive database for travel information, all kinds of information are online, and this improves the collaborative mechanisms for information building, mining, and sharing. At the same time, online information system covers widely, and has large amount of information, and its connection subjects are numerous. Therefore, the number of information nodes increases, the released energy will become more, and information flow between the nodes of the collaborative network will be strengthened, too. Through the benign cycle, regional tourism cooperation organization keeps the collaborative network perfect and the collaborative mechanism optimized. Perfect information network strengthens supervision of each sub-body, and monitors members of the cooperation organization before they violate the cooperation keynote. The public supervision platform reduces "close and not" in the past in a certain degree. The online information system improves technology by its capacity of integrating information. Its technical index mainly includes consulting system of tourism multimedia 
information, tourism geographic information system, space information system (RS, GIS, and GPS), massive database technology, meta-based technology, and other network technologies. On the one hand, these high-end information technologies help the organization collect and pass information, on the other hand, they improve the capacity of mining, sharing, filtering and feeding back information. By the large collection and formal operation, cooperation organization has more opportunities to capture the subtle information of the market, then innovate the organization structure and product structure, improve strain capacity, organizational flexibility and the ability to resist risks in the end.

\section{RESEARCH PROCESS}

\section{A. Regional tourism cooperation organization led by the government}

In the initial stage of regional tourism cooperation, organization members consider their narrow self-interests and look for the way of sharing the organization profit. This self-serving psychology destructs the regional tourism cooperation organization into "pseudocooperation" organization [9]. Due to the asymmetry of information, each daughter starts from their own interests of the game in the repeating "Prisoner's Dilemma," which makes organizational performance consume more in the fight for interests. In this period, organizational performance is very low, and self-discipline and the ability of controlling is weak, the behavior of individual opportunism seriously affect the operation of the organization. The cooperation at this time is in the "zerosum” rule. As shown, at this time, the government plays dual role as a semi-involved body and the dominant body. It uses administrative ways to coordinate the relationship of sub-body and maintains a balanced distribution of benefits [10]. The government's administrative intervention makes the regional tourism cooperation run smoothly, but greatly limits the organization's own ability and performance. The administrative intervention simplifies the organization structure, which should be based on market mechanisms before. The organization's daughter is just a simply building part, the communication of information is basically a one-way between the daughter and mother, and there is no information feedback or capabilities of building and mining [11]. According to each sub-body's ability of self-control, market operation and collaboration, the government intervenes and controls in different degrees (the distance between sub-body and government in the diagram). In the initial structure of cooperation organization, the daughter is in extensive parallel relationships. Even though there are many differences in tourism resources, geographical environment, tourism development potential, because of the administrative power, these differences are not obvious, and the sub-body's advantages are limited, and cannot be played out completely. In the initial stage of cooperation, communication barriers, and asymmetric information lead the government into the cooperation organization as a participant, and it also becomes a transit bond, connects various stakeholders to build the regional cooperation organization together.

\section{B. Regional tourism cooperation organization with the structure of "star topology"}

With the development of regional tourism cooperation organization, the improvement of various mechanisms, and the join of information system of tourism cooperation, the relationship of sub-bodies changes gradually. The four subsystems of online information system increase amount of communication and speed up the frequency of information both inside and outside. The information asymmetry between the organization daughters is improved. In the transparent environment of information game, organizations turn "zero-sum game" into "winwin" cooperation [12]. At the same time, the government quits gradually, and it becomes the controller outside the organization, not a leader as before. It supervises and regulates the tourism cooperation organization, supplying the organization sufficient space for development, and is not involved in the operation. In addition, market mechanisms make the tourism organization emerge the chief and ally. As there are differences in tourism resource endowment space, the position of daughter, who has advantages, is prominent, and takes over the government's position as a leader. It commands other organization daughters, and is a significant part of coordination and operation. Secondly, the tourism resources of each sub-body in the regional cooperation organization are complementary; it forms star structure which has the chief [13]. The exchange of information at this time is more extensive and more frequent between the sub-bodies. In the platform of online information system, each sub-body shows their respective advantages through online information system, professional information system of the cooperation organization. And internal organization management, which is operated by knowledge system, ties the main bodies more closely. At this time, the regional tourism cooperation organization becomes a formal organization gradually, by information technology; it captures market information autonomously, distributes resources reasonably, shares resources and advantages, and shows the overall advantage of the regional tourism resources.

\section{Regional tourism cooperation organization with functional modular}

The organization structure emphasizes the horizontal relations among the elements. The organizations, business, integration, and collaboration of the functional core all need the support of information technology. The information transmission speed of the original organization structure is slow; it reduces the operation speed, and also restricts the organizational performance. The development of online information system provides important technology support for the organization functionalization. And it turns one-way information exchange into a multi-directional communication, which 
is modern and has large-capacity to a great extent. Organization members share information through the platform of regional tourism information system, members can know the organization's overall planning and mission objectives timely, analysis and judge the function independently, and make decisions. As shown, with the help of service platform of online information system, each daughter becomes substructure which has professional functions. $\mathrm{A}$ and $\mathrm{C}$ collect market information, analyze the travel source market by the professional information system, and do the project planning for tourism products according to the market demands. On the other hand, B and D establish a virtual project workspace through collaborative information system [14]. They combine the production factors for the planning products, and produce products which meet tourists' demands. These four daughters build different sub-organizations temporarily by different subsystems of the online information system and cooperate with each other according to the availability of resources. As shown, because of deleting the information transit link of the original organization structure, the exchange of information between the sub-bodies is with the help of online information platform. Such flexible organization structure strengthens the adaptability of cooperation organization. For the drastic changes in the travel source market, it can respond quickly, and build a suborganization structure rapidly by online information system.

\section{Network regional tourism cooperation organization}

Network structure is some independent courses of business or enterprise partners based on information and communication technologies, connected to other independent businesses or individuals, such as supply enterprises, production enterprises, consumers, and even competitors. And it is a temporary alliance relying on a highly developed network. Network enterprise is an organization form of dynamic alliance; each subject breaks through the tangible boundary, and integrates with outside help by a variety of ways [15]. Depending on information technology and communication network, members of the network organization can cross the spatial boundaries and communicate conveniently. They can share information with the help of complete information and enough partners. This ensures all members have a better cooperation, and achieve the best combination of time, quality, cost, service and environment, and at last have the strongest competitiveness. Network organization becomes flattened because of high adaptability of information flow. In the network organization, each daughter can communicate interactively with any sub-block directly based on the efficient transmission of information. So organizations can take splitting measures to face the change. Network schema is the ideal form for regional tourism cooperation and is consistent with the characteristics of large bodies of regional tourism cooperation organization. It rises up to three-dimensional or even multidimensional mode from one-dimensional, two-dimensional space of the organization structure. The link between daughters is not built by one or two information flow, but is joined by multiple nodes. And at this time, online information system has the maximum effect, each daughter accepts information from other daughters, the supply of information and the frequency of exchange are both great that the previous onedimensional organization structure cannot provide [16]. Network organization is the advanced stage of the development of regional tourism cooperation organization. It has high demands for online information system, and the operation of the organization is completely under the control of the market mechanism at the same time. Each sub-body has full trust and understanding, information is transparent, and there's no barrier in transmission.

\section{CONCLUSIONS}

With the rapid development of information technology, tourism information system has provided a broader space for the development of regional tourism cooperation undoubtedly. Whether for the technical aspects, or for the establishment of organization structure, online information system plays an important role. Through its intervention, organizations have closer links and a deeper level of information symmetry. The organization structure is more reasonable and stable, and its performance has also been significantly improved. With the initiation of regional tourism cooperation, it is necessary to standardize organization operations, enhance organization adaptability to mine, build, share, deliver, and to feedback information. "People cannot live without information" has become an important rule that can't be ignored in the organization competition. So it's necessary to build regional tourism cooperation organization based on online information system. Now the research is relatively weak, this paper says something about the organization structure of cooperation based on the online information system, and hopes to provide useful help for the synergistic development of regional tourism cooperation organization. There are a number of different reporting practices within the various sectors taking part in the organization cooperation. It is hoped that the paper will be a useful reference for both practitioners and designers of information strategies in a business environment and will also serve as a guide for graduate students undertaking information management research inclined to the strategic deployment of information in heterogeneous business environments.

\section{REFERENCES}

[1] B. Bramwell A. Sharman, Collaboration in local tourism policymaking. Annals of Tourism Research, 26, pp. 392-415, 1999.

[2] Pavlovichk. The evolution and transformation of a tourism destination network: the Waitomo Caves, New Zealand, Tourism Management, Vol. 24, No. 2, pp.203-216, 2003.

[3] Gursoy Dokson, Mccleary Kowan, An Integrative model of tourists' information search behavior. Annals of Tourism Research, 31, pp. 702-723, 2004. 
[4] Wei Min. A Research on the Online Information System Applied to Regional TourismCooperation,International Journal of Advancements in Computing Technology, 2011;3:118-129.

[5] Tazim.Jamal, Getz D. Collaboration Theory and Community Tourism Planning”. Annals of Tourism Research, 1995; 22:186204.

[6] Yue Yafan. Evolution process for regional tourism cooperation organization based on information system. Journal of Chemical and Pharmaceutical Research, 2014, 6(7): 2733-2740.

[7] Sautteret, Leisenb, Managing Stakeholders: A Tourism Planning Model, Annals of Tourism Research, 1999; 26: 312-328.

[8] Jianzhong Xie, Yu Yang, Yunhai Tao, Wei Chen, Fei Li, A Study on Business Process Dynamic Evaluation of Business Process Integration Management Based on Fuzzy-EAHP, International Journal of Advancements in Computing Technology, 2012; 4:5665.

[9] Bushra Abdullah Al-Anesi, Khalid Omar Thabit, An Arabic NLP System for Information Management within Organizations, International Journal of Information Processing and Management, 2012; 3:10 -18.
[10] Lanping Yan, Minna Guo, Yuhong Li, An Empirical Research on International Competitiveness of China's Trade in Service, International Journal of Information Processing and Management, 2012; 3: 44 -55.

[11] Klaus Weiermair; Patricia Kneisl, "Tourist Cooperation and Networks”. Tourism and Hospitality Management, 1996,2(1):125128.

[12] Gursoy Dounce, Chen Jiansheng, Competitive analysis of cross cultural information search behavior, 2000; 21:583-590.

[13] Qi Deficiency Blood Stasis Syndrome, International Journal of Information Processing and Management, 2012, 3:12-17.

[14] Kerstetter Dabar, Mihea Conce. Prior knowledge, credibility and information search, Annals of Tourism Research, 2004; 31:791806.

[15] Gursoy Dokson, Mccleary Kowan. An Integrative Model of Tourists' Information Search Behavior. Annals of Tourism Research, 2004; 31:702-723.

[16] Bushra Abdullah Al-Anesi, Khalid Omar Thabit, An Arabic NLP system for information management within organizations. International Journal of Information Processing and Management, 3, pp. 10-18, 2012. 